\title{
Digitalization of Higher Education: The Impact of the Epidemiological Crisis in the Spring of 2020
}

\author{
Suleimenov I.E. ${ }^{1,{ }^{*}}$ Shaltykova D.B. ${ }^{1}$ Egemberdyeva Z.M. ${ }^{1,2}$
}

\author{
${ }^{1}$ Institute of information and computational technologies, Almaty 050010, Kazahstan \\ ${ }^{2}$ Almaty University of Power Engineering and Telecommunications, Almaty 050013, Kazahstan \\ *Corresponding author. Email: esenych@yandex.kz
}

\begin{abstract}
The nature of the impact of the epidemiological crisis of spring 2020 on the higher education system is analyzed. It is shown that this crisis encourages the digitalization of higher education as a social institution, and there are conditions under which this institution becomes much more stable with any type of crisis. It is shown that it is necessary to distinguish between specialties that can be attributed to industrial and postindustrial, and the latter mainly include all those related to info-communication technologies. It is shown that the training of specialists in industrial and post-industrial specialties should be carried out according to different schemes, moreover, it should be based on different paradigms. It is shown that due to the possibility of a repeat of the epidemiological crisis in the spring of 2020, the training of specialists in the field of infocommunication technologies requires a rapid radical restructuring. This is primarily due to the multiplying volume of information related to this area and the increasing role of interdisciplinary interaction. The already established trend of convergence of information and telecommunications technologies is overlaid with the need for their early integration with medicine (the development of telemedicine systems, neural network diagnostics, etc.).
\end{abstract}

Keywords: epidemiological crisis, telemedicine, higher education, examination marks, academic freedoms,

info-communication technologies

\section{INTRODUCTION}

The epidemiological crisis in the spring of 2020 forced many universities around the world to switch to distance education. In many countries, this decision was made at the government level. Universities are faced with the need to restructure their activities as soon as possible, the nature of work and some departments, including those that produce them, are not ready for this. At the same time, it is necessary to understand that the current crisis brings with it not only threats but also creates a window of opportunity. Moreover, there is an opinion that the epidemiological crisis of the spring of 2020 performed the same function as the First and Second world wars. Many economists, futurists and publicists are convinced that the only way out of any large-scale economic crisis is a world war. When the world war became impossible due to the presence of a nuclear deterrent, its function was de facto fulfilled by the global epidemiological crisis. It will inevitably cause a structural adjustment of the entire world economy, which is impossible to argue with. In other words, regardless of what causes led to the emergence of the current epidemiological crisis (whether it was artificially stimulated to increase the information impact on the population) or whether it all happened for purely natural reasons, the result is obvious. It is also obvious that with such a large-scale restructuring of the economy, there can be at least two scenarios: an optimistic and a pessimistic one. The optimistic scenario is related to the fact that the current crisis has stimulated the transition to remote work and thereby strengthened the role of the digital economy, spurred the processes of digitalization. These processes have been quite slow, and now there are all the prerequisites for their acceleration. The measures taken by Governments around the world have particularly affected higher education - it is almost completely going digital. Moreover, the question is whether to return to the original state of Affairs at the end of the crisis, or whether to take advantage of the situation and create a full-fledged system of distance education, which has some advantages. For countries such as Kazakhstan, these advantages are most evident. As noted in [1-3], the quality of higher education and teaching staff has fallen so low that many teachers are not even able to express their thoughts coherently. The transition to a remote format, where lowquality lectures are recorded in electronic form, will at least highlight the real state of Affairs and allow you to identify professionally unfit teachers. Also, distance education makes it much more difficult to use corruption schemes. The measures taken by Governments around the world have particularly affected higher education - it is almost completely going digital. Moreover, the question is whether to return to the original state of Affairs at the end 
of the crisis, or whether to take advantage of the situation and create a full-fledged system of distance education, which has some advantages. This, however, is not the main thing. In many countries, such as Kazakhstan, the sphere of higher education has long been one of the most important segments of the economy. Thus, in Kazakhstan, more than $50 \%$ of young people from the corresponding age group are students. As a result, such a profession as a University teacher in Kazakhstan has become popular, and higher education is de facto one of the most important sectors of the economy (at least in terms of job creation). In other words, the restructuring of the economy cannot but affect the sphere of higher education. Most obvious here is the fact that it seems inevitable that the number of paying students will decline. The crisis will hit the solvency of the population, and for many of the citizens of Kazakhstan, higher education is not urgently needed. More precisely, for Economics, educational services can be attributed to those whose demand will inevitably fall sharply when the population's solvency falls. This is confirmed by the fact that there is a clear surplus of higher education institutions in Kazakhstan today. According to official statistics [4], at the beginning of the 2017/2018 academic year, there were 127 higher education institutions in the Republic with a population of about 18 million (or 1 University for just over 140 thousand people). For comparison, in countries that are recognized leaders in higher education, there are 650-700 thousand people per University [5]. For example, in the UK, there are 89 universities for 60.4 million people, and 20 universities for 5.2 million in Finland.

This factor is on the surface, but there are many others besides it. In particular, the structure of applicants ' preferences cannot but change. One of the consequences of the crisis will be a decline in the number of jobs that were not directly linked to the real economy. In particular, a collapse in employment is predicted in those areas of activity, the functioning of which was associated with the use of various types of financial instruments, not to mention a clear oversupply of office workers, associated with the pre-existing financial capabilities of companies (including quasi-public) to indefinitely inflate the staff. As a result, in the foreseeable future, the number of citizens who want to get formally "prestigious" specialties related to international law, macroeconomics, international journalism, etc.will decrease. Reorientation to the real sector of the economy, in other words, cannot but affect the sphere of higher education. The inevitable "belttightening" cannot but affect universities and higher education in general. Accordingly, in this area, any state that seeks to maintain macroeconomic stability will inevitably be forced to move to fairly strict austerity measures, and this is where digitalization provides a definite resource. Indeed, at present, when there are numerous tools for outsourcing (for example, video lectures that are in the public domain), only the conservatism of the University management forces them to focus primarily on full-time teachers. From an economic point of view, this is not very profitable. Inter-University cooperation alone, in particular, allows for significant savings through, for example, the exchange of video lectures and other materials that can be implemented remotely. In this sense, the epidemiological crisis in the spring of 2020 can also play a positive role. Quite possible. it will force University leaders to move to austerity, force them to use outsourcing and reconsider, among other things, their attitude to the "sacred cow" of any University, that is, to the staffing table. This is the positive role of the epidemiological crisis in the spring of 2020 - universities can get rid of the ballast, as well as introduce the most advanced educational technologies. Everything that was discussed above applies to all specialties in one way or another. This is a general view of the problem, and it is, of course, impossible to disclose the issues that arise in this regard in a separate article. Our goal is to solve a narrower problem. We will try to show that there is a well-defined group of specialties for which forced digitalization can provide a decisive step forward. Specifically, we are talking about specialties related to information and communication technologies in one way or another. We will try to prove that it is possible to introduce a different paradigm of higher education than the one that goes back to Jan Amos Komensky, who created the classic class-based system, which is still preserved despite digitalization. We would like to emphasize that, unfortunately, many people now dictate the digitalization of higher education rather one-sidedly. In essence, the digitization scheme that is used by many universities (even in the context of an epidemiological crisis) is a kind of duplicate of the class-based system of Jan Amos Komensky but only translated into a remote format. There is no question that digitalization can and should change the very paradigm of learning, its very basic principles. It is appropriate to emphasize that the need to transform the basic paradigm of higher education is long overdue [6-8], which can be justified from a philosophical point of view [9.10]. But there is also no doubt that the sphere of higher education is one of the most conservative. Accordingly, it makes no sense to raise the question of its restructuring as a whole, at least at this stage. In this paper, it is proved that it is necessary to differentially consider specialties that are conditionally related to "industrial" and "post-industrial". The latter, obviously, mainly include specialties related to info-communication technologies in one way or another. They are the ones who should be on the "edge of the attack"; first of all, they need to move from an outdated paradigm of higher education to a post-industrial one (for all the conditionality of this term).

\section{THE NEED TO RESTRUCTURE THE HIGHER EDUCATION SYSTEM IN THE FIELD OF INFORMATION AND COMMUNICATION TECHNOLOGIES: A GENERAL VIEW OF THE PROBLEM}

Disciplines related to information and communication technologies in the modern world occupy a somewhat special place, and it is not only about trends that are 
expressed in the support that the political elites of the world now provide to developments in the field of artificial intelligence. The situation in this area (if we talk about higher education) has changed dramatically, but, first of all, this is due to the convergence between information technologies and telecommunications technologies. There is a somewhat disparaging expression that information technology experts use to signallers "You only have cables left". It sounds a bit rude, but there is some truth in this. Thus, automatic telephone exchanges (ATE) are not exactly a thing of the past, but more and more common computer technology is used to provide communication. There are such messengers as Viber, WhatsApp, speaking of which, it is extremely difficult to draw a line between information technologies and what used to be strictly a means of communication. It is appropriate to emphasize that the epidemiological crisis has also worsened the situation in this regard. In particular, it demonstrated that telemedicine and related digital technologies are more than in demand. In other words, another factor was added to the convergence process that was already underway. It is necessary to develop systems for the mass monitoring of the health status of the population, it is necessary to develop artificial intelligence systems that can diagnose (preferably remotely) the symptoms of certain diseases, etc. It is obvious that telecommunications and information technologies play a significant role here, to put it mildly, but the development of the above-mentioned scientific areas cannot be separated from classical medicine. In other words, in modern conditions, there are not just prerequisites for further building up interdisciplinary cooperation, but a fundamentally different scientific and technical environment is emerging, in which it becomes quite difficult for teachers of modern post-Soviet universities to navigate. Even a cursory analysis of the topics of conferences that take place in the field of information and communication technologies shows that the list of topics considered at them includes a huge number of different positions, and this is a definite challenge for modern higher education. Even a basic comparison of the number of hours that are currently allocated for training in bachelor's and master's degrees can not cover the entire range of knowledge that, if we proceed from the classic industrial paradigm of higher education, a specialist in the field of telecommunications should have. The convergence between at least three previously loosely related fields of knowledge has led to the fact that the amount of information necessary to prepare a specialist who meets the criteria of the twentieth-century paradigm becomes excessively large. Somewhat simplifying, we can say this. In modern conditions, more than one Department working in the field of information technology is not even theoretically able to form an adequate curriculum, remaining within the framework of views formed in the twentieth century. There are no criteria according to which, out of all the variety of scientific achievements made in the field of info-communication technologies, it is necessary to choose the information that should be included in the curriculum. (Especially if we take into account the need for rapid development of telemedicine). De facto, departments working in the field of infocommunication technologies are forced either to focus on available resources, that is, to complete the curriculum based on what teaching staff is available, or to resort to outsourcing. It is obvious that in conditions where there are no objective criteria for selecting information that should be included in the curriculum, its formation will not de facto occur randomly-simply because there is an excessively large amount of information in this area of knowledge. This area of knowledge is not just developing very rapidly; let us stress once again that interdisciplinary cooperation is becoming pronounced here, and it is no longer possible to do without it. In particular, those departments that used to train pure "communicators" now have to teach disciplines related, for example, to artificial intelligence and neural networks, which are actively used by any modern gadgets. You can no longer do without this, as well as without teaching specific sections of mathematics. The amount of information is truly gigantic, and it becomes almost impossible to fit it into the curriculum. It follows from this that we need to change the very paradigm, the very basic approach to training highly qualified specialists, at least in these specialties. However, there is no doubt that there are also specialties in which training (at least in the foreseeable future) can and should remain within the framework of the classical paradigm, which goes back to Jan Amos Comenius and von Humboldt. In particular, this applies to the training of specialists in the field of refrigeration industry, where there are no fundamental changes. Approximately the same can be said about the training of specialists in the field of heat and even nuclear power. To train specialists who serve thermal power plants, it is quite possible to use the textbooks that were published thirty years ago, since the principle of operation of thermal power plants has not changed during this time. This circumstance is more than significant, since it reflects a well-defined, if I may say so, the phase shift in higher education. Some specialties can be attributed to post-industrial ones with some degree of conditionality, and there are still specialties that can be attributed to purely industrial ones. From this we can draw the most important conclusion. Schemes of training specialists related to post-industrial and industrial specialties can not be left the same. If heat power engineers, specialists in the field of automotive, shipbuilding, etc. if you can still afford to cook within the old paradigm, then you can no longer do this to specialists in the field of info-communication technologies. 


\section{RESULTS OF THE EXPERIMENT AND THEIR DISCUSSION: PREREQUISITES FOR THE RESTRUCTURING OF HIGHER EDUCATION IN THE FIELD OF INFO- COMMUNICATION TECHNOLOGIES AND TELEMEDICINE}

This experiment was conducted in the second semester of the 2018/2019 academic year in the framework of practical classes on the discipline "Artificial intelligence as a driver of the fourth technological revolution" at the Almaty University of energy and communications (master's degree, the first year of study). This discipline was specially developed and implemented to create a complete picture of their future professional activities in the context of convergence of telecommunications and information technologies. During the experiment, a survey was conducted to identify the picture of the professional environment that has already developed among students, as well as their opinions about the advantages and disadvantages of the master's program. Examples of questionnaires directly related to professional activities are shown in Table 1 and Table 2. Questionnaires related to determining the opinion of undergraduates on the quality of the educational process and the state of Affairs in University science are considered in [11].The experiment showed that undergraduates can be divided into two groups. One of them includes students who show critical thinking and interest in obtaining real knowledge; for those who are included in the second, there is a marked indifference to learning and interest only in obtaining a formal certificate of qualification (diploma). The second group made up, according to the survey results, about $40 \%$ of the total number of undergraduates. The questionnaire presented in table 1 was intended to assess how important a scientific field such as telemedicine is for undergraduates studying in the specialty "radio engineering, electronics and telecommunications". The questionnaire presented in table 2, as well as similar ones (a total of 8 questionnaires were used), was intended to assess the preferences of undergraduates to a wider range of issues that are not included in the curriculum.

Table 1 Example of a questionnaire aimed at studying the preferences of undergraduates in scientific areas related to telemedicine

\begin{tabular}{|c|c|}
\hline Scientific direction & $\begin{array}{c}\text { \% (from the number } \\
\text { of respondents) }\end{array}$ \\
\hline Multimedia & 0 \\
\hline Hardware and software solutions & 34 \\
\hline Telemedicine, Telehealth and Remote Monitoring & 13 \\
\hline Innovative eHealth, Applications and Products & 3 \\
\hline Electronic Health Records and Medical Databases & 0 \\
\hline Medical Image Analysis and Biomedical Visualization & 8 \\
\hline Reliability analysis and risk estimation & 0 \\
\hline Testing and fault-tolerant systems & 3 \\
\hline Accident and incident investigation & 3 \\
\hline Human factor & 0 \\
\hline Risk and hazard analysis & 13 \\
\hline Computational Intelligence & 11 \\
\hline Data mining and Knowledge discovery & 0 \\
\hline E-education, e-learning & 0 \\
\hline $\begin{array}{l}\text { There are no scientific areas of particular interest to me in this list, and I personally } \\
\text { do not see the point in adding them to the master's degree program in our specialty }\end{array}$ & \\
\hline
\end{tabular}

Questionnaire question (respondents were asked to choose only one of all options): the following are the research topics selected for discussion at the "Information and Digital Technologies 2019" conference held under the auspices of the IEEE in Zilina, Slovakia. Which of these research areas is of particular interest to you personally, and would you recommend including it in the educational program for your master's degree program? 
Table 2 Example of a questionnaire aimed at studying the preferences of undergraduates in research areas related to information and communication technologies in General

\begin{tabular}{|c|c|c|}
\hline № & The name and website of the conference & $\%$ \\
\hline 1 & $\begin{array}{c}\text { Blockchain Expo (Santa Clara, CA, North America 13-14th November 2019) } \\
\text { https://www.blockchain-expo.com/ }\end{array}$ & 0 \\
\hline 2 & $\begin{array}{l}\text { The 3rd International Conference on Information Processing and Control Engineering } \\
\text { (Moscow, Russia during August 4-7, 2019) } \\
\text { http://www.icipce.org/ }\end{array}$ & 5 \\
\hline 3 & $\begin{array}{l}\text { IoT Tech Expo (Amsterdam on the 19-20 June 2019) } \\
\text { https://www.iottechexpo.com/ }\end{array}$ & 13 \\
\hline 4 & $\begin{array}{c}\text { International Conference on Artificial Intelligence and Virtual Reality (AIVR) (in Singapore } \\
\text { during July 27-29, 2019) } \\
\text { http://www.aivr.org/ }\end{array}$ & 8 \\
\hline 5 & $\begin{array}{l}\text { IEEE 4th International Conference on Computer and Communication Systems (will be held in } \\
\text { Singapore) } \\
\text { http://www.icccs.org/ }\end{array}$ & 0 \\
\hline 6 & $\begin{array}{l}\text { International Conference on Machine Learning and Computing (China on Feb. 15-17, 2020.) } \\
\text { http://www.icmlc.org/ }\end{array}$ & 5 \\
\hline 7 & $\begin{array}{l}\text { The 3rd International Conference on Mechatronics Systems and Control Engineering (Nice, } \\
\text { France during February 26-28, 2019) } \\
\text { http://www.icmsce.com/ }\end{array}$ & 8 \\
\hline 8 & $\begin{array}{c}\text { The Asia Pacific Information Technology Conference (APIT) (January 25-27, 2019| Jeju } \\
\text { Island, South Korea) } \\
\text { http://www.apit.net/ }\end{array}$ & 5 \\
\hline 9 & $\begin{array}{l}\text { Artificial Intelligence and Cloud Computing Conference (AICCC) } \\
\text { http://www.aiccc.net/ }\end{array}$ & 0 \\
\hline 10 & $\begin{array}{l}\text { International Conference on Computer and Automation Engineering (ICCAE) (December 21- } \\
\qquad \begin{array}{c}\text { 23, 2019 | Kobe University, Japan) } \\
\text { http://www.iccae.org/ }\end{array}\end{array}$ & 18 \\
\hline 11 & $\begin{array}{c}\text { Международный научный форум «Шаг в будущее: искусственный интеллект и цифровая } \\
\text { экономика» Россия, г. Москва } \\
\underline{\text { https://guu.ru/digital }}\end{array}$ & 13 \\
\hline 12 & $\begin{array}{c}\text { Eighth International Conference on Advances in Computing, Communication and Information } \\
\text { Technology - CCIT (23-24 April, } 2019 \text { at Birmingham, United Kingdom) } \\
\text { http://ccit.theired.org/ }\end{array}$ & 8 \\
\hline 13 & $\begin{array}{c}\text { Open Semantic Technologies for Intelligent Systems (Республика Беларусь, г. Минск) } \\
\text { http://www.conf.ostis.net }\end{array}$ & 5 \\
\hline 14 & The topics of these conferences are of no interest to me & 11 \\
\hline
\end{tabular}

Questionnaire questions (respondents were asked to choose only one of all the options): there are quite a large number of conferences of different levels in the world, where the key problems of information and communication technologies are often discussed. Which of

the conferences listed below would You prefer to attend without a presentation, just as a listener, to learn something new for yourself (it is assumed that the participation costs are paid in full)? The results of the experiment allowed us to draw the following conclusions.
Undergraduates have a certain understanding of the importance of interdisciplinary research. Only $34 \%$ of the respondents chose the item "Hardware and software solutions" in the questionnaire, table 1 , which is closest to their specialty in terms of formal characteristics. At the same time, the indicator of $34 \%$ correlates with the data obtained by processing other questionnaires, which revealed the number of undergraduates who are indifferent to learning. At the same time, it should be emphasized that this survey was conducted long before the epidemiological crisis in the spring of 2020.

For the rest of the questionnaire items, table 1 , the responses are distributed approximately evenly. The 
distribution, which is fairly close to uniform, was also shown by the results of the survey on such questionnaires as shown in Table 1. This means that among students there is already a certain demand for the acquisition of knowledge of an interdisciplinary nature, and quite a certain dissatisfaction with existing programs. Therefore, there is every reason to believe that the thinking part of students is interested in the restructuring of higher education in the field of information and communication technologies.

\section{MEASURES TO IMPLEMENT THE POST-INDUSTRIAL PARADIGM OF HIGHER EDUCATION IN THE FIELD OF INFORMATION AND COMMUNICATION TECHNOLOGIES}

Based on the above, we will have to conclude (and not only us, but most likely. and the world community) that there is no other choice but to encroach on the two "sacred cows" of the modern University system. Specifically, we are talking about the staffing table and training programs. Indeed, it is impossible not to recognize that the curriculum in modern conditions of any of the departments specializing in the field of info-communication technologies is formed randomly, and this is already realized by students who seek to fill in the gaps in knowledge through self-education. The very concept of" curriculum " (at least to the sphere of info-communication technologies) is already becoming an anachronism, there is absolutely no need for it. Accordingly, there is no need to complete the staff of the Department in the form in which it is done today; you can increasingly use outsourcing.

Moreover, the analysis of the state of Affairs in this area shows that the old thesis of theoretical pedagogy is more evident than ever: any education is primarily selfeducation. We can give concrete examples that prove that the most successful (in the field of info-communication technologies) are often those students who disdained the content of the curriculum and studied themselves. Of course, this phrase sounds somewhat shocking, but it reflects the essence of the matter. To train an adequate specialist in modern conditions, it is necessary first of all to teach him to think, to teach him to work with information. The concept of "curriculum" was inherited from previous eras, from the style of teaching that developed around the middle of the XX century. The young specialist went to the factory or design Bureau and presented the appropriate certificate to the management, called the diploma Supplement. Looking at it, the head of a particular Department could assess exactly where to send a new employee, in which issues he is better oriented, in which-worse. It was a kind of "portrait of a specialist". In conditions when the curriculum has died out (if only because it is formed eclectically), no grades passed on specific exams can serve as a reflection of the real "portrait of a specialist", of course, can not. Exam scores in the post-Soviet space have become mainly a corruption factor.
The most reasonable thing that can be done (if we talk about the field of information and communication technologies) is to cancel the exam grades altogether. We emphasize once again that we do not claim that this approach should be applied everywhere. There are such disciplines as philosophy, where the classical approach should and can be maintained. This also applies to basic subjects (such as physics, higher mathematics, etc.).

But, soon there are specialties that should be attributed to the post-industrial, they should be treated as such. In particular, it is here that we need to abolish such anachronism as exam grades and control over how a student performs educational tasks in a particular discipline, in a particular subject. All this nonsense leads only to the growth of bureaucracy, to the formalization of the educational process, and ultimately to corruption. There is every reason to say that where formal reporting comes to the fore, corruption inevitably appears. (Of course, these statements apply only to subjects that are traditionally called special, that is, completing the formation of a specialist). Consequently, many of the dogmas of the industrial paradigm of higher education that have become anachronisms need to be eliminated. It is no longer possible to create a" portrait of a graduate " based on examination grades in special disciplines, and it is not necessary, especially if we take into account the fact that the nature of jobs is very diverse and they are characterized by increasing dynamics. It is impossible to predict what exactly should be taught to a future specialist in the field of info-communication technologies, even if we assume that universities will get the appropriate resources at their disposal. Exam scores in special subjects have lost all meaning. Therefore, the main role should belong to the final control. In other words, at least in the field of information and communication technologies, all attempts to ensure control over the learning process can and should be replaced by adequate control over the result. The" end product " of studying at a University is a young specialist; a reflection of his capabilities as a person who can and wants to do something in his field may well be working on graduate work in a bachelor's degree or a dissertation - in a master's degree. Therefore, it is sufficient to ensure control only at the level of the last stage. In the field of information and communication technologies, all other forms of control are harmful. Here you can draw an analogy with any plant. It is absurd to control the process of manufacturing products, the consumer (to higher education - society), should only control the final result, what is at the output. How exactly the University trains this specialist, that is, it achieves the desired result-it is not important.

This leads to the thesis of the need for an even greater degree of academic freedom, that is, to strengthen the theses that von Humboldt once formulated. The University does not need to impose anything at all, especially if we are talking about info-communication technologies. Only the final result is important, and it can and should be controlled at the level of defense of the final works of the bachelor's degree or master's thesis. 
Another important measure is to maximize the use of outsourcing. Even now in the field of info-communication technologies, students ' training at graduate departments can be built entirely based on direct communication between the student and his supervisor, who gives recommendations on what to read, what educational sites to visit, etc.

If all lectures go to a distance format, and control has lost its meaning, then it is enough to minimize the staff of teachers, or rather to redistribute the educational load so that most of it falls on research. This is also completely correlated with the basic principles of von Humboldt, according to which the process of studying at the University can not go in isolation from the occupation of science. In a certain sense, this approach will allow us to return to the basic principles of von Humboldt, the need for which was discussed in $[10,12]$, and at the same time to rebuild the learning system to maximize the use of online educational resources available to students.

We emphasize that there is no need to prepare distance classes for a particular group of students studying at a particular University. Preparing a full-fledged distance course is an extremely expensive process and such a product is expensive. If it is done by a single University, the quality will be very low, of course. Therefore, we need other incentives and, accordingly, we need to review approaches to the University's economy, for which the current crisis also creates all the necessary prerequisites.

\section{CONCLUSION}

Thus, the epidemiological crisis associated with the Covid19 outbreak cannot but stimulate radical changes in the field of higher education, at least if we talk about those specialties that are somehow related to infocommunication technologies. In this area of knowledge, there is an extremely rapid accumulation of information, and there is a pronounced trend towards the convergence of information and telecommunications technologies. As a result, the very concept of "curriculum" for this group of specialties has de facto lost its meaning, since there are no objective criteria according to which one should choose educational material from a huge amount of information. Post-Soviet universities form programs in such specialties, as a rule, situationally, they are often eclectic. The projected development of telemedicine only worsens the situation, since the formation of training programs is an extremely long process. As a result, universities will inevitably lose the ability to respond to challenges, including global ones, at the right speed if they continue to adhere to the paradigm formed in the twentieth century.

In the current conditions, it is necessary to distinguish between specialties that can be attributed to industrial and post-industrial (info-communication technologies and everything related to them). Education in post-industrial departments can and should be rebuilt first and foremost, and this can be done without additional investment by providing universities, teachers and students with even greater academic freedom than is provided for by the classical von Humboldt principles - up to the complete abolition of intermediate examination grades.

The main criterion for the effectiveness of universities that provide training in post-industrial specialties should be their ability to generate demanded innovations.

\section{REFERENCES}

[1] K.I. Suleimenova et al. Post-transition period and quality of higher education: ways to overcome the crisis phenomena, International Letters of Social and Humanistic Sciences, 8(8) (2013) 49-56.

[2] P.V. Obukhova, J.P. Guichard et al. Influence of Mass Consciousness on Quality of the Higher Education in Kazakhstan, Procedia-Social and Behavioral Sciences, 185 (2015) 172-178. DOI: https://doi.org/10.1016/j.sbspro.2015.03.354

[3] I.E. Suleimenov et al. History and philosophy of science. Almaty: publishing house of the Treasury, (2018)

[4] Ministry of National Economy of the Republic of Kazakhstan statistics Committee. http://stat.gov.kz/

[5] Estimated number of universities worldwide as of July 2018, by country https://www.statista.com/statistics/918403/number-ofuniversities-worldwide-by-country/

[6] I. Suleimenov et al. Quantitative theory of effectiveness of highest education: role of interpersonal communications, European Journal of Educational Sciences (EJES), 1(2) (2014) 171.

[7] I. Suleimenov et al. Degradation of Higher Education in Kazakhstan as an example of posttransitional crisis, International Letters of Social and Humanistic Sciences, 54 (2015) 26-33. DOI: https://doi.org/10.18052/www.scipress.com/ILSHS.54. $\underline{26}$

[8] Suleimenov I. E. et al. The role of horizontal learning in the implemention of the "Miracle strategy" in Kazahstan's higher school, Bulletin Abay Kazakh National Pedagogical University, Series of Physics and Mathematical Sciences, 3(67) (2019) 82-89.

[9] G. Mun et al. The category of pseudoscientific as a problem: to the thesis of the renaissance of philosophical knowledge, Journal of Philosophy, Culture and Political Science, 1(71) (2020) 21-31.

[10] I.E. Suleimenov and O.A. Gabrielyan. The role of Philosophy of science in the new paradigm of higher 
education, Bulletin of Almaty University of energy and communications, Materials International scientific and practical conferences "Role of youth in the formation of the knowledge economy, (2018) 13-23.

[11] I. Suleimenov et al. Example of the use of Artificial Neural Network in the Educational process, Future of information and communication conference (FICC), Springer, Cham, (2020) 420-430. DOI: https://doi.org/10.1007/978-3-030-39445-5 31

[12] G. Mun et al. Printsipyi fon Gumboldta i realii postsovetskih universitetov, Journal of Philosophy, Culture and Political Science, 69(3) (2019) 21-30. DOI: https://doi.org/10.26577/jpcp-2019-3-p3 